\title{
Determination of parts tolerances in friction knots of grey and nodular cast iron with thermal diffusion platings vanadium and chrome
}

\author{
Alexander A. Veselovsky ${ }^{1}$, Roman R. Dema ${ }^{2}$, Olga B. Kalugina ${ }^{2, *}$, and Sergey P. Nefedyev ${ }^{3}$ \\ ${ }^{1}$ Head of research center JSC KONAR, Yenisei street 8, 454000, Chelyabinsk, Russia \\ ${ }^{2}$ Federal state Budgetary Institution of Higher Education "Nosov Magnitogorsk State Technical University" (FSBIHE "NMSTU”), \\ Lenin Avenue, 38, Magnitogorsk city, 455000, Russia. \\ ${ }^{3}$ Limited Liability Company «Factory of lubricants» OKTAMIX», Leningrad street 49, office 14, 455000, Magnitogorsk, Russia
}

\begin{abstract}
In the study, experiments with a vanadium coating of samples were conducted, to establish the limits of the increase in the landing dimensions and the designation of limiting deviations in dimensions and the designation of limiting deviations in the dimensions of the manufactured parts. The maximum deviations relative to dimensions of cast iron parts with thermal diffusion platings vanadium and chrome in friction knots of machines and mechanisms were explored. The plate thickness and the linear sizes increment of gray and nodular cast iron hardened products were determined. Were obtained uniform in thickness carbid platings as a result of the experiments on producing of thermal diffusion vanadium and chrome plating.
\end{abstract}

\section{Introduction}

Thermal diffusion platings allow to create the highly rigid and wear-resistant platings on parts surface in friction knots by carbide-stabilizing elements. However the diffusion of carbide-stabilizing elements into cast iron presents certain difficulties

Carbon presence on the cast iron surface conduces bonding in carbides of adsorbed diffusants considerably complicating further diffusion deep into a product[1].

Theoretically the diffusion of vanadium and chrome into the cast iron is possible only during the initial period of saturation until their content will not reach the stoichiometric composition for carbide forming.

However considering border-line conditions of first genus it is possible to deduce that the diffusion of these elements deep into the material is inconspicuous.

Therefore the creation of thermal diffusion platings of preset thickness is provided by the counter diffusion of carbon from the deep layers of material to the zone of reactive diffusion[2].

The objective of this work is to determine magnification limits of coupling sizes and the purpose of the maximum deviations relative to dimensions and the the purpose of the maximum deviations relative to dimensions of manufacturing parts with due regard for further thermal diffusion vanadizing and cromodizing by contact process using powder mixture[3].

\section{Equipment, materials and the procedure of experiments}

The pieces with inside diameter of $20 \mathrm{~mm}$ and outer diameter of $40 \mathrm{~mm}$ from gray iron and nodular cast iron were used for experiment.

Vanadizing was developed using ferrovanadium $(60 \%$ on mass) inert filler aluminum oxide( $40 \%$ on mass), and activator $\mathrm{NH} 4 \mathrm{Cl}(4 \%$ on mass, extra $100 \%)$, cromodizing was developed using ferrochrome $(50 \%$ on mass), aluminum oxide (50\% on mass) and activator ( $4 \%$ on mass).

The saturation temperature was $1000-1020^{\circ} \mathrm{C}$, time of hardening was 5 hours for vanadizing process and 10 hours for chromodizing process. Processes of thermal diffusion saturation was developed at the plant(reworked retort furnace) which scheme is presented in figure 1.

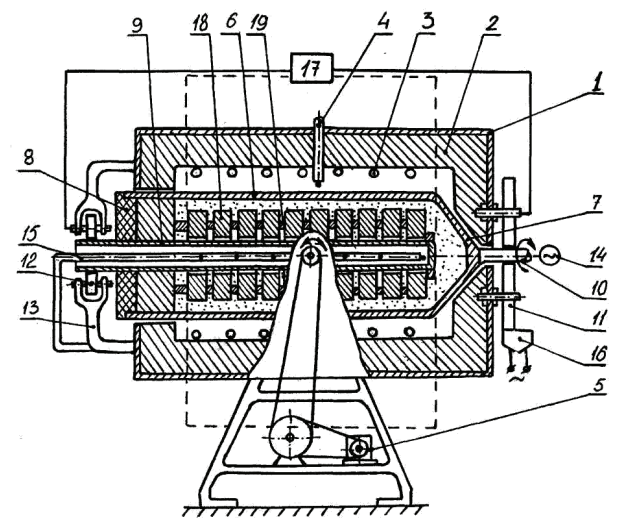

Fig. 1. Structural drawing of the plant for the thermal diffusion saturation.

The plant operation takes place in the following way. The heating chamber 1 with cylinder muffler 2 , electric heating unit 3 and heat meter 4 is brought in a vertical

\footnotetext{
${ }^{*}$ Corresponding author: kalugina.olga@bk.ru
} 
position with a help of the swivelling device 5 (is marked by dashed lines in drawing) when the retort is placed front cover down(with the removed back cover 8).Ring parts 18 are done on closed bottom tube (from gray and nodular iron) closely to each other or through the distance pieces 19 which help to protect some elements of parts from future plating on the one side and to provide the equability of plating on another side. The retort 6 is filled up with working mixture(furnacecharge).

Then the retort 6 is leakproof locked by the back cover 8 with parts are done on close bottom tube. The heating chamber 1 is brought to horizontal position by swivelling device 5. The shaft 10 is fixed by front rollers 11 , the closed bottom tube 9 is fixed by back rollers isolated from the heating chamber 1 by electrical isolator 13 .

The shaft 10 of the retort 6 is brought to rotation by driving mechanism 14 with rotation frequency 3-10 rpm. The External heat of the retort 6 is performed from muffler 2 by electric heater 3 supplied from variable transformer ( is not presented in the drawing). The temperature control of treatment schedule is provided by heat meters 4 installed on the muffler 2, heating chamber 1 and additional heat meters 15 placed is the closed bottom tube 9 and fixed on the heating chamber 1. This temperature control provides uniform heating by length and cut of retort 6 that guaranties the improving quality of parts processing. Under the external heat of the retort 6 rotating on front 11 and back rollers 12 , the thermochemical treatment processing of parts 18 goes on.

Additionally to the rotation agitation, with oscillation superposition (low-frequency or ultrasonic) from the resonator 16 to the retort 6 through the front rollers 11 or their axes transformer ( are not presented in the drawing) in it create the vibrofluidized bed. Vibroliquefaction is performed with vertical vibration frequency of the retort 6 within the diapason $15-25 \mathrm{~Hz}$ and the amplitude 1$3 \mathrm{~mm}$. The vibrofluidized bed enables to forcibly lead active substance to the saturation surface increasing the speed of saturation and intensifying diffusion surface alloyage. This provides a high level of gas permeability of the furnace charge that enhances the uniformity of the plating.

\section{Results and discussion}

As a result of the experiment on the creation of thermal diffusion platings on gray and nodular iron, it was obtained vanadium platings (figure 2) which microhardness came to $26000-28000 \mathrm{mPa}$.

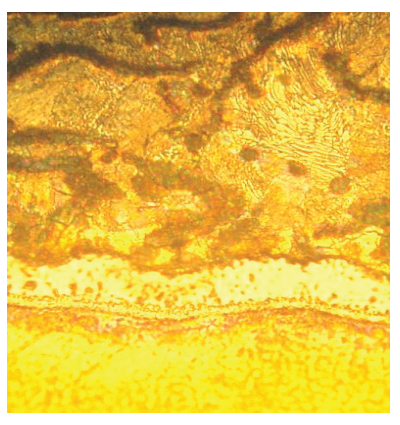

a

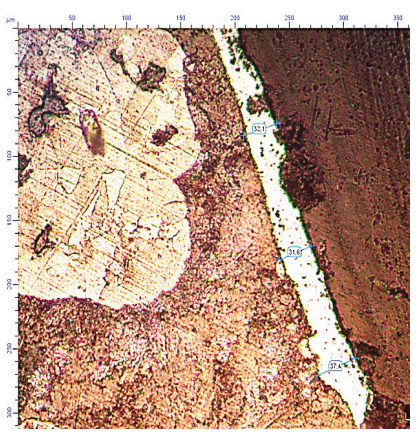

b
Fig. 2. Microstructure of vanadium plating (x500): on gray (a) and nodular(b) iron.

Microstructure of platings obtained after chromodizing of pieces is presented on Figure 3.

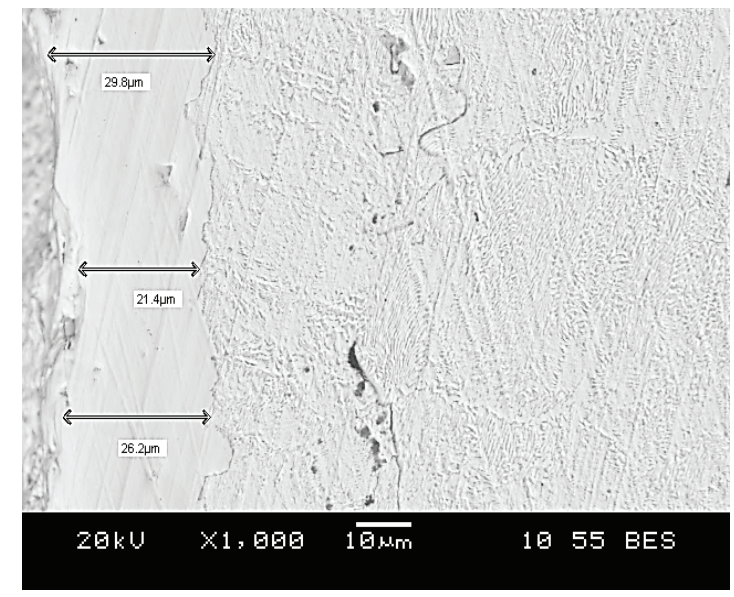

Fig. 3. Microstructure of chromium plating on nodular iron(x1000)

Formation mechanism of thermal diffusion vanadium plating can be explained by scheme presented on figure 4.

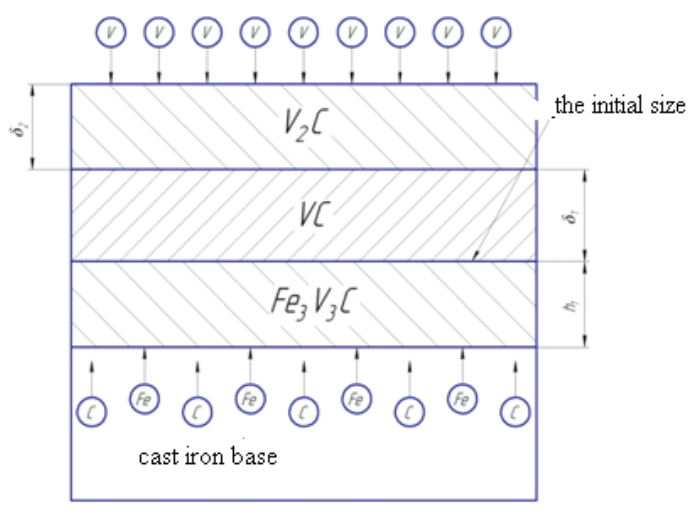

Fig. 4. Scheme of formation of diffusion vanadium plating.

High concentration of vanadium on the iron part surface, low concentration of carbon in this area on one side and lower free energy potential on the other side create favourable conditions for vanadium carbide formation $\mathrm{V}_{2} \mathrm{C}$.

Vanadium carbide $\mathrm{VC}$ has higher free energy potential than Vanadium carbide $\mathrm{V}_{2} \mathrm{C}$ [5].

The formation of carbide phase slows down the 
vanadium diffusion from plating deep into a part, because its atomic mobility of chemical compound is low and insufficient for bond opening and vanadium transferring deep into a part.

The diffusion of ferrum into iron into the area of reactive diffusion slows down for the same reason. As a result the diffusion carbide $\mathrm{h}_{2}$-layer is formed in the outer zone of a part and the external edge of layer shifts to the side of the physical growth by a quantity $\delta 1$.

As a result of the carbon counter diffusion, $\mathrm{V}_{2} \mathrm{C}$ vanadium carbide transforms into $\mathrm{VC}$ vanadium carbide:

$$
\mathrm{V}_{2} \mathrm{C}+\mathrm{C}=2 \mathrm{VC}
$$

The slowdown in the process of the rejection of a saturation element from outer zone deep into a part will lead to increasing of its concentration on the surface of a part. As a result of the carbon counter diffusion and deposition of a hardening element on a part surface, $\mathrm{h}_{1}$ carbide layer is formed, and its external edge shifts by a quantity $\delta_{2}$ [4]. Shifting of the external edge of the diffusion layer by a quantity $\delta_{2}$ will depend on the diffusion depth of the hardening chemical element in the material of $h_{2}$ part, parameters difference of ferrum lattice and formed chemical compounds - carbids.

The major change of $\delta_{2}$ layer sizes takes place as a consequence of active vanadium or chrome formation on the part surface and depends on mass-transfer coefficient of saturated chemical compound from reaction space to a part surface, and also owing to carbon counter diffusion of iron to a diffusion layer and formation of a carbide phase.

Thus, the increment of the linear sizes of a lpart can be determined by a formula:

$$
\Delta \mathrm{d}=\delta_{1}+\delta_{2}
$$

The layer is situated under the plating is a cementite alloyed by vanadium $\mathrm{Fe}_{3} \mathrm{~V}_{3} \mathrm{C}$ [6]. Carbon concentration reaches stoichiometry for cementite creation. Vanadium increasing liability of iron to a chilling effect helps formation of the chilling effect in the zone bording to a plating and decomposes in it partially.

The sequence of the phase formation under cromodizing is presented of figure 5. As a result of this the increasing of tolerances of coupling size is observed.

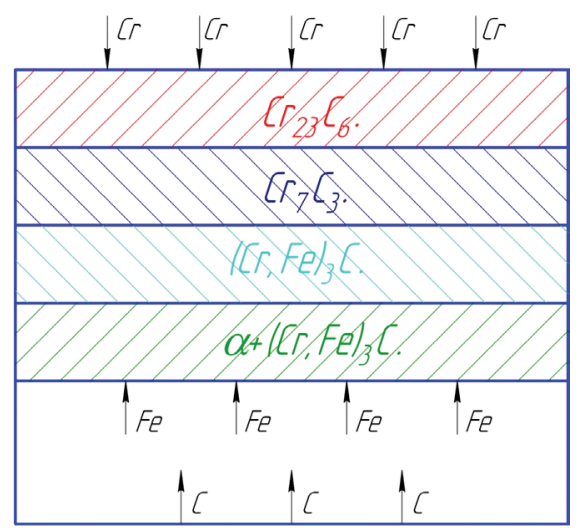

Fig. 5. Phases which formed under thermal diffusion saturation of gray and nodular iron with chrome.
Time-temperature curve was done to determine the best time and temperature of vanadium process and chromodizing process of gray and nodular iron. They are presented on figures 6,7 .

As we can see on figures 6, the hardened layer thickness increase permanently on all time line. However for vanadium platings, the increasing of hardening time over 6 hours provides spall fracture and peeling of plating. For chrome platings, the increasing of hardening time over 10 hours provides strong slowing of the plating formation speed and inconspicuous increasing of it.

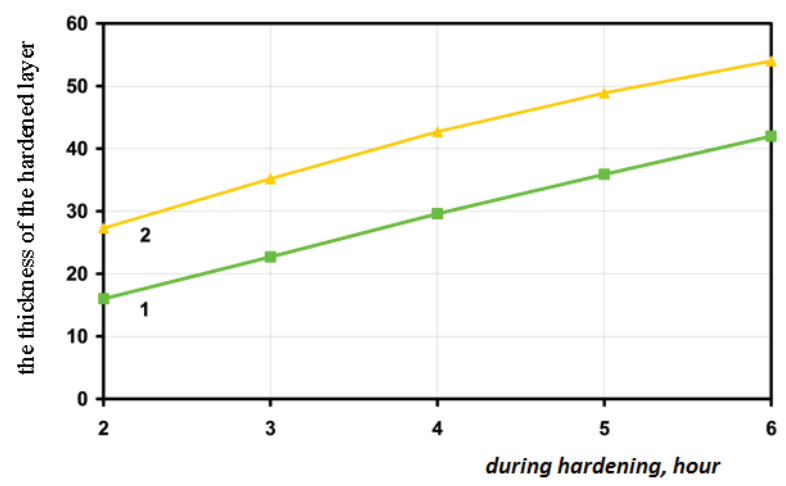

Fig. 6. Dependece of thickness of hardened vanadium plating $\delta$ on saturation time $\left(1000^{\circ} \mathrm{C}\right)$ : 1- gray iron $\left(\mathrm{y}=10,474 \mathrm{x}^{0,7531)} 2\right.$ nodular iron $\left(\mathrm{y}=18,163 \mathrm{x}^{0,649}\right)$

To indicate the variance of the coupling sizes of a part as a result of thermal diffusion and determination tolerances to the basic parts sizes, experiments on identification of increments of the linear sizes were done. The variance is indicated by size comparison detected by micrometer before and after thermal diffusion saturation (figure 7)

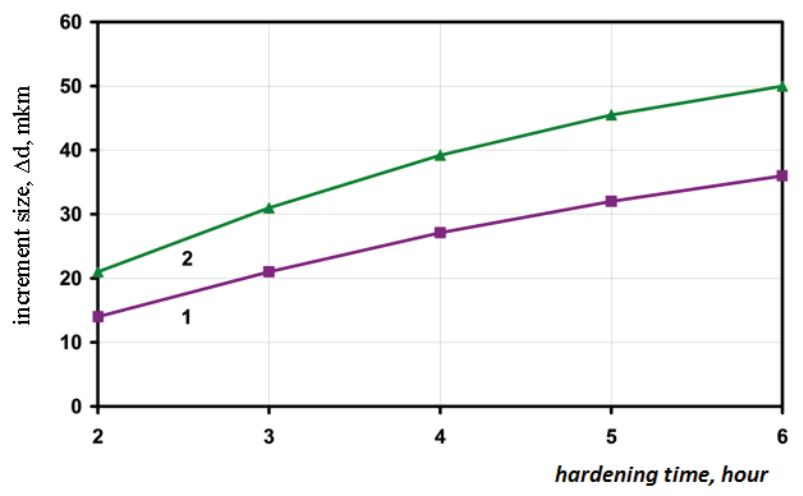

Fig. 7. Dependence of increments of the linear sizes (on a side) $\Delta \mathrm{d}$ on hardening time $\left(1000^{\circ} \mathrm{C}\right)$ under vanadizing (a) and chromodizing (б): 1 - gray iron, 2-nodular iron.

Comparing obtained results with the results on figure 8, we can conclude that increments of the linear sizes of hardened iron pieces under vanadizing and chromodizing approximately equals the thickness of produced platings. 


\section{Conclusions}

As a result of the experiments on producing of thermal diffusion vanadium and chrome plating, uniform in thickness carbid platings were made. Their microhardness reaches $26000-28000 \mathrm{mPa}$ under vanadizing and $13000-16000 \mathrm{mPa}$ under chromodizing. Besides that, the increment of exterior sizes of hardening parts is observed after hardening relative to ingoing size (before hardening). The mechanism of this hardening is proved theoretically. In this regard at purpose of maximum deviations of tolerances of the sizes of iron parts which are exposed to thermal diffusion saturation by vanadium and chrome, it is necessary to consider an increment of the sizes by the quantity of produced plating: 40-60 micron for vanadium process and 45-60 for chromodizing process.

The authors are thankfully acknowledge the financial support by the Ministry of Education and Science of the Russian Federation for the project № 11.2054.2017/Project task within the framework of the state task for 2017-2019 (Number for publication: 11.2054.2017/ 4.6) to carry out this investigation.

\section{References}

1. An-Hui Lu, Guang-Ping Hao, Qiang Sun, XiangQian Zhang, Wen-Cui Li, Chemical Synthesis of Carbon Materials With Intriguing Nanostructure and Morphology, Macromolecular Chemistry and Physics,. 213, 10-11. pp. 1107-1131, (2012)

2. William M. Steen, Laser Surface Treatment, Chapter of Laser Material Processing. Springer London, pp 172-219, (1991)

3. S.P. Nefediev, R.R. Dema, N.Sh. Tyuyaterakov, A.N. Morozov, M.V. Kharchenkov, M.A. Belotserkovskiy, M.A. Levantsevich, Chromomargane coating fusion area structure obtained by plasma powder weld deposit, Problems of ferrous metallurgy and materials science 1. pp. 68-72. (2016)

4. V.K.Ilyin, Restoration and hardening of parts in agricultural machinery by methods of thermal diffusion saturation (Dokt, Diss. Kazan, 290 p., 2004)

5. A.A.Veselovsky, I.M. Yachikov, Increasing of durability of parts from gray iron for telescopic and hydraulic cylinders, Monography (Magnitogorsk, 118p., 2009)

6. A.A.Veselovsky, A.N.Zavalishchin, Research of the microhardness of the aluminized layers on the gray iron obtained by thermal diffusion hardening, The hardening technologies and platings 5. p18-21. (2007) 